\title{
Rhinacanthin-C Extracted from Rhinacanthus nasutus (L.) Inhibits Cholangiocarcinoma Cell Migration and Invasion by Decreasing MMP-2, uPA, FAK and MAPK Pathways
}

\author{
Parichart Boueroy ${ }^{1,2}$, Sunitta Saensa-Ard ${ }^{1,3}$, Pongpun Siripong ${ }^{4}$, Sakawrat \\ Kanthawong $^{1 *}$, Chariya Hahnvajanawong ${ }^{1,2 *}$
}

\begin{abstract}
Cholangiocarcinoma is a malignant tumor with high metastatic and mortality rates. We investigated the effects of rhinacanthin- $\mathrm{C}$ on cell proliferation, migration, invasion and the expression of proteins regulating cancer cell invasion-regulated proteins in a cholangiocarcinoma (KKU-M156) cell line. Cytotoxicity of rhinacanthin-C was determined by the SRB assay. Using wound-migration, chamber-migration and chamber-invasion assays, we assessed the effects of rhinacanthin-C against KKU-M156 cells. The activities of matrix metalloproteinases 2 and 9 (MMP-2, MMP-9) and urokinase-type plasminogen activator (uPA) were determined using gelatinase and uPA zymography assays. The expression of invasion-regulated proteins was investigated using western-blot analysis. After treatment with rhinacanthin-C, KKU-M156 cells exhibited antiproliferative effects in a dose-dependent manner with greater efficacy than in Vero cells: IC50 values were 1.50 and $2.37 \mu \mathrm{M}$, respectively. Rhinacanthin-C significantly inhibited cell migration and invasion of KKU-M156 cells in a dose-dependent manner. Consistent with this observation, treatment with rhinacanthin- $\mathrm{C}$ was associated with a decrease in the expression levels of FAK, p-FAK, MMP-2, and a decrease in the levels of p38-, JNK1/2- and ERK1/2-MAPK pathways as well as inhibiting NF- $\mathrm{BB} / \mathrm{p} 65$ expression and translocation of $\mathrm{NF}-\kappa \mathrm{B} / \mathrm{p} 65$ to the nucleus. We have shown for the first time that the anti-metastatic effects of rhinacanthin-C on KKU-M156 cells are mediated via inhibition of the expression of invasion-regulated proteins. Rhinacanthin-C may deserve consideration as a potential agent for the treatment of cholangiocarcinoma.
\end{abstract}

Keywords: Rhinacanthin-C- invasion- migration- metastasis

Asian Pac J Cancer Prev, 19 (12), 3605-3613

\section{Introduction}

Cholangiocarcinoma is the second-most prevalent primary hepatic tumor worldwide and is associated with a high mortality rate. This cancer is highly metastatic, leading to unresponsiveness to chemotherapeutic drugs. New therapeutic approaches are badly needed to suppress this malignancy.

Many studies have focused on natural compounds as potential sources of novel anticancer drugs. Rhinacanthus nasutus (Linn.) KURZ (family Acanthaceae) has been widely used in Thai traditional medicine for the treatment of various cancers such as cervical and liver cancers (Siripong et al., 2006a). Rhinacanthin-C (Figure 1 ), extracted from leaves and roots of this plant, is a naphthoquinone ester shown to possess anti-inflammatory, antifungal, antibacterial, antiviral and cytotoxic activities (Bukke et al., 2011). Recently, rhinacanthone has also been reported to inhibit proliferation, cell cycle arrest and induce apoptosis in human cervical carcinoma HeLa cells in dose- and time-dependent manners (Siripong et al., 2009). Recently, the same researcher reported that rhinacanthins ( $\mathrm{C}, \mathrm{N}$ and $\mathrm{Q}$ ) exhibit anti-proliferative effects and induce apoptosis in human cervical carcinoma (HeLaS3) cells mediated through G2/M cell-cycle arrest and by the activation of caspase-3 (Siripong et al., 2006a).

Cancer cell invasion is facilitated by degradation of extracellular matrix (ECM) using various proteolytic enzymes, among them matrix metalloproteinases (MMPs) and urokinase plasminogen activator (uPA). MMP-2 (72 kDa: gelatinase A) and MMP-9 (92 kDa: gelatinase B) play a key role in cancer-cell invasion and metastasis that can degrade type IV collagen, the major component of basement membranes (Librach et al., 1991; Liotta et al., 1980). There is increasing evidence to indicate that both MMP-2 and MMP-9 are highly expressed in various types

${ }^{1}$ Department of Microbiology, ${ }^{2}$ Center of Excellence for Innovation in Chemistry, Cholangiocarcinoma Research Institute, ${ }^{3}$ Center of Excellence for Innovation in Chemistry, Liver Fluke and Cholangiocarcinoma Research Institute, Cholangiocarcinoma Screening and Care Program (CASCAP), Faculty of Medicine, Khon Kaen University, Khon Kaen, ${ }^{4}$ Natural Products Research Section, Research Division, National Cancer Institute; Bangkok, Thailand.*For Correspondence: sakawrat@kku.ac.th, hchari@kku.ac.th 
of tumors and contribute to cancer invasion and metastasis (Basset et al., 1997; Chung et al., 2002). In addition, the uPA system plays an important role in initiating the activation of plasminogen to plasmin and of MMPs, thus allowing cancer cells to invade distant organs (Duffy and Duggan, 2004).

Mitogen-activated protein kinase (MAPK) is commonly separated into three subfamilies of MAPK-signaling pathways; extracellular signal-regulated kinases (ERK), Jun NH2-terminal kinases (JNK), and p38 kinases. These play a critical role in tumor progression and metastasis by induction of proteolytic enzymes that degrade the ECM (a key marker of invasive carcinoma), enhancement of cell migration, initiation of several pro-survival genes and maintenance of tumor growth (Reddy et al., 2003). Therefore, inhibition of MAPK pathways might have the potential to inhibit proliferation, angiogenesis, invasion and metastasis of tumors. Any new drug that can do this should exhibit anti-invasion activity against cholangiocarcinoma cells and would be valuable given the limited response of this kind of tumor to current drugs. Effects of rhinacanthin-C on cholangiocarcinoma cell lines have not been reported previously. The present study investigated the antitumor effects of rhinacanthin-C using an in vitro model of human cholangiocarcinoma cells. The expression of MAPK pathways and MMP-2 and -9 in human cholangiocarcinoma cells after treatment with rhinacanthin-C was also monitored.

\section{Materials and Methods}

\section{Materials}

Rhinacanthin-C (Figure 1) was extracted from Rhinacanthus nasutus (Siripong et al., 2006b; Siripong et al., 2006c). Rhinacanthin-C was dissolved in dimethyl sulfoxide (DMSO) to create a stock solution of $8 \mathrm{mM}$ that was stored at $-20^{\circ} \mathrm{C}$. Primary antibodies against MMP-2, MMP-9, ERK1/2, phosphorylated ERK1/2, JNK, phosphorylated JNK, p38, phosphorylated p38, FAK, phosphorylated FAK, and NF-KB p65 or $\beta$-actin were purchased from Sigma Chemicals and antibodies against histone H1 were purchased from Abcam (Cambridge, UK). Secondary antibodies (anti-mouse or anti-rabbit) were purchased from Santa Cruz Biotechnology, Inc. (Dallas, TX, USA). The chamber migration assay was done using Transwell chambers (Costar) with $6.5 \mathrm{~mm}$ diameter polycarbonate membranes ( $8 \mu \mathrm{m}$ pore size). The chamber invasion assay was done using BD Biocoat Matrigel Invasion Chamber (Becton Dickinson) (8 $\mu \mathrm{m}$ pore size).

\section{Cell culture}

Human cholangiocarcinoma cells (KKU-M156) was established at the Department of Pathology, Faculty of Medicine, Khon Kaen University. The Vero cell line was derived from the kidney of a normal, adult, African green monkey (Cercopithecus) (Sheets, 2000). Both cell lines were grown in RPMI-1640 medium supplemented with $10 \%$ heat-inactivated fetal bovine serum (FBS), $100 \mathrm{U} / \mathrm{ml}$ penicillin and $100 \mu \mathrm{g} / \mathrm{ml}$ streptomycin in a humidified environment with $5 \% \mathrm{CO}_{2}$ at $37^{\circ} \mathrm{C}$.

\section{Cell viability assay}

The effect of rhinacanthin-C on cell viability was determined using the sulforhodamine B (SRB) assay as described previously (Pinmai et al., 2008). Briefly, human CCA cells were seeded into 96 -well plates at a density of $1 \times 10^{4}$ cells per well. After $24 \mathrm{~h}$ incubation, cells were treated with various concentrations $(0-2.4 \mu \mathrm{M})$ of rhinacanthin-C for 24, 48 and $72 \mathrm{~h}$, after which the SRB assay was conducted.

\section{Wound migration assay}

Cells were seeded into 6-well plates at a density of $5 \times 10^{5}$ cells $/ \mathrm{ml}$ and grown to $80-90 \%$ confluence. The monolayers were scratched using a 1-ml plastic pipette tip to create a denuded zone (gap), then rinsed with PBS and medium containing 1\% FBS to remove cell debris. Cells were incubated in medium containing $1 \%$ FBS with or without rhinacanthin-C $(0.15,0.3,0.6 \mu \mathrm{M})$ for $24 \mathrm{~h}$. The extent of wound area was determined and photographed. Cell migration into the wound area was monitored by microscopy and digitally photographed. The area of the wound was measured.

\section{Chamber migration assay}

Chamber migration assays were done using Transwell Boyden chambers. Five-hundred microlitres of serum-free medium containing $400 \mu \mathrm{l}$ of cells $\left(1.25 \times 10^{5}\right.$ cells $\left./ \mathrm{ml}\right)$ and $100 \mu \mathrm{l}$ of various concentrations of rhinacanthin-C or DMSO was added in the upper chamber. The lower chamber contained medium supplemented with $10 \%$ FBS as a chemo-attractant. After $24 \mathrm{~h}$ of incubation, nonmigrated cells on the upper compartment of the membrane were removed using a cotton swab. The migrated cells on the bottom surface of the membrane were fixed with $4 \%$ paraformaldehyde for $30 \mathrm{~min}$ and stained with $0.4 \% \mathrm{SRB}$ in $1 \%$ acetic acid for $30 \mathrm{~min}$. After destaining with $600 \mu \mathrm{L}$ of $1 \%$ acetic acid, filters were air-dried overnight. The stained cells were counted on each membrane under a light microscope and using digital images, and the percentage of cells migrating was determined.

\section{Chamber invasion assay}

The invasion assay was performed in a manner similar to the cell migration assay, except that the upper side of the Transwell filters were coated with Matrigel (Becton Dickinson). The experiments were carried out in triplicate using two independent experiments.

\section{Gelatin zymography and uPA assay}

The activities of MMP-2 and MMP-9 in the conditioned medium were measured by gelatin zymography assay (Bradford, 1976). Briefly, the amount of gelatinase (MMP-2 and MMP-9) in conditioned medium was measured after treatment with rhinacanthin- $\mathrm{C}$ at various concentration for $24 \mathrm{~h}$. The conditioned medium containing $50 \mu \mathrm{g}$ protein was mixed with $4 \mathrm{x}$ sample buffer and separated by SDS-PAGE using a $10 \%$ polyacrylamide gel containing $1 \mathrm{mg} / \mathrm{ml}$ gelatin. The amount of $\mathrm{uPA}$ in conditioned medium was separated by $10 \%$ SDS-PAGE gel containing $1 \mathrm{mg} / \mathrm{ml}$ gelatin and $20 \mu \mathrm{g} / \mathrm{ml}$ plasminogen. 
After electrophoresis, gels were rinsed with $2.5 \%$ Triton $\mathrm{X}-100$ and then incubated in a reaction buffer $(50 \mathrm{mM}$ Tris- $\mathrm{HCl}$, pH $8.0 ; 5 \mathrm{mM} \mathrm{CaCl}_{2}$ and $0.02 \% \mathrm{NaN}_{3}$ ) at $37^{\circ} \mathrm{C}$ for $12 \mathrm{~h}$. The gel was stained with $0.5 \%$ Coomassie blue and destained in acetic acid. The proteinase activity was visualized as clear areas on the blue background and analyzed using the program Scion Image (Scion Corp., Frederick, MD, USA).

Preparation of total cell, cytosol or nuclear lysates

To prepare total cell lysates, cells $\left(1 \times 10^{6}\right.$ cells/dish) were seeded into $100 \mathrm{~mm}$ dishes for " $24 \mathrm{~h}$ ". and then treated with various concentrations of rhinacanthin-C or DMSO for $24 \mathrm{~h}$. Cells were then rinsed twice with cold PBS and lysed with cold RIPA buffer $(50 \mathrm{mM}$ Tris-HCl, pH 7.5, 0.5\% Nonidet P-40, $150 \mathrm{mM} \mathrm{NaCl}$, $1 \mathrm{mM}$ dithiothreitol, $1 \mathrm{mM}$ EDTA, $0.1 \%$ sodium dodecyl sulfate, $0.5 \%$ deoxycholate) containing a protease inhibitor cocktail (Pierce Biotechnology) and phosphatase inhibitor cocktail (Pierce Biotechnology). Cell lysates were centrifuged at $13,000 \mathrm{~g}$ at $4^{\circ} \mathrm{C}$ for 30 min, and the supernatants were collected. To prepare cytosol and nuclear lysates, cells were lysed with buffer A (10 mM HEPES, $0.1 \mathrm{mM}$ EDTA, $10 \mathrm{mM} \mathrm{KC1}$, $0.2 \% \mathrm{NP} 40,1.5 \mathrm{mM} \mathrm{MgCl}_{2}, 1 \mathrm{mM}$ DTT, and $0.5 \mathrm{mM}$ phenylmethylsulfonyl fluoride), followed by vortexing to shear the cytoplasmic membranes and nuclear pellets were collected by centrifugation at 3,000 rpm for $30 \mathrm{~min}$ at $4{ }^{\circ} \mathrm{C}$. Nuclear proteins were extracted with high-salt buffer B (20 mM HEPES, 25\% glycerol, $1.5 \mathrm{mM} \mathrm{MgCl}$, $0.1 \mathrm{mM}$ EDTA, $420 \mathrm{mM} \mathrm{NaCl}, 1 \mathrm{mM}$ DTT, and $0.5 \mathrm{mM}$ phenylmethylsulfonyl fluoride). All lysates were stored at $-80^{\circ} \mathrm{C}$ until use. Protein concentration was determined using by the method of Bradford (Bradford, 1976).

\section{Western blot analysis}

Equal amounts of proteins were separated in a $12 \%$ SDS-polyacrylamide gel and transferred onto a nitrocellulose membrane (Millipore, Billerica, MA, USA). After blocking with Tris-buffered saline containing $0.1 \%$ Tween-20 and $5 \%$ skimmed milk at $37^{\circ} \mathrm{C}$ for $1 \mathrm{~h}$, the membranes were incubated at $4{ }^{\circ} \mathrm{C}$ overnight with primary antibodies against MMP-2, MMP-9, ERK1/2,

$\mathbf{A}$

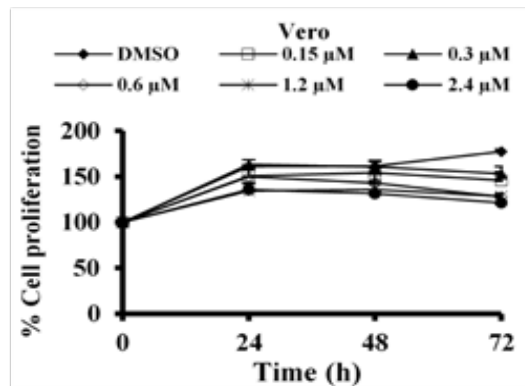

phosphorylated ERK1/2, JNK, phosphorylated JNK, p38, phosphorylated $\mathrm{p} 38$, and NF- $\mathrm{kB}$ p 65 or $\beta$-actin or histone $\mathrm{H} 1$ and subsequently incubated with the appropriate secondary antibody (anti-mouse or anti-rabbit). The bound secondary antibody was visualized using an enhanced chemiluminescence kit (Pierce Biotechnology), quantified by densitometry (ImageQuant LAS 4000; GE Healthcare, Piscataway, NY, USA) and analyzed using the program Scion Image (Scion Corp., Frederick, MD, USA). Relative intensity was determined and normalized to $\beta$-actin (total cell and cytosolic lysates) or histone H1 (nuclear lysate).

\section{Results}

Inhibitory effect of rhinacanthin-C on the viability of a human CCA cell line

The cytotoxic effects of rhinacanthin- $\mathrm{C}$ at various concentrations $(0-2.4 \mu \mathrm{M})$ on human CCA cells (KKU-M156) and Vero cells for 24, 48 and $72 \mathrm{~h}$ were determined by SRB assays. The proliferation of Vero cells was not affected (relative to controls) at any time or concentrations tested (Figure 2A). The proliferation of KKU-M156 cells was significantly inhibited by rhinacanthin- $\mathrm{C}$ in a dose- and time-dependent manner as compared to control cells (Figure 2B). The $\mathrm{IC}_{50}$ values of rhinacanthin- $\mathrm{C}$ were $1.50 \pm 0.22$ and $2.37 \pm 0.17 \mu \mathrm{M}$ for KKU-M156 and Vero cells, respectively.

\section{Anti-migration effects of Rhinacanthin-C on KKU-M156 cells}

The effects of rhinacanthin-C on the migration of Vero and KKU-M156 cells were determined using a wound-closure assay. As shown in Figure 3B and 3C, rhinacanthin- $\mathrm{C}$ caused a significant delay in migration of KKU-M156 cells into the wound area compared with the

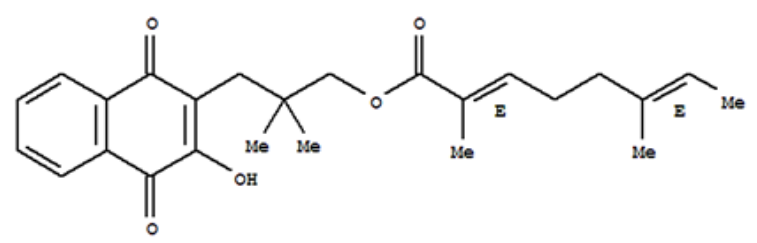

Figure 1. Structure of Rhinacanthin-C

B

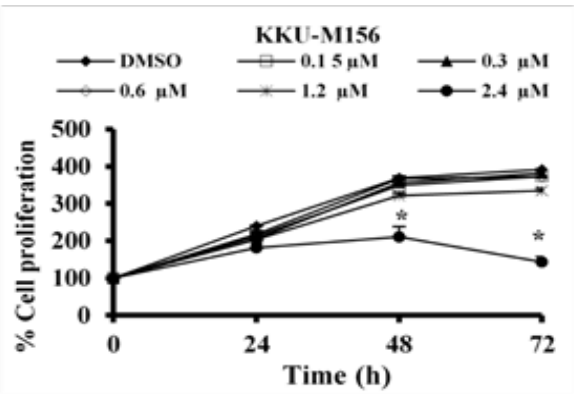

Figure 2. Antiproliferative Effects of Rhinacanthin-C Against Vero Cells and Cholangiocarcinoma Cell Lines (KKU-M156). The cells at density of $1 \times 10^{6}$ cells/well were seeded in 96-well plates. After $24 \mathrm{~h}$ of incubation KKU-M156 cells were incubated with rhinacanthin-C at various concentration of $0,0.15,0.3,0.6,1.2$ and $2.4 \mu \mathrm{M}$ for 0, 24, 48 and $72 \mathrm{~h}$. Cell proliferations of (A) Vero and (B) KKU-M156 cells were determined by SRB assay. Each value represents the mean \pm SD of three independent experiments. ${ }^{*} p<0.05$ vs. the DMSO group. 
$\mathbf{A}$

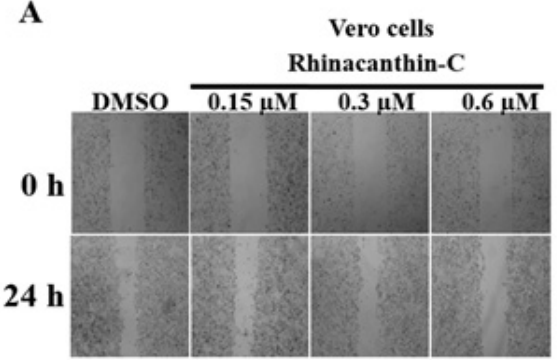

B

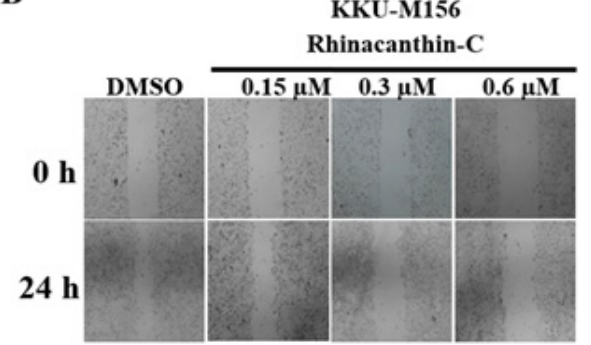

C

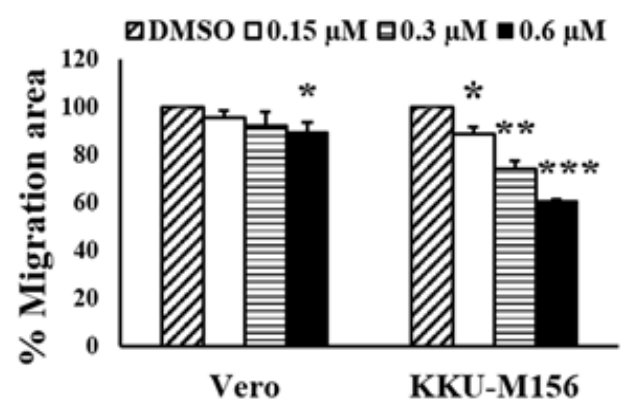

Figure 3. Effect of Rhinacanthin-C on Cell Migration of Vero Cells and KKU-M156 Cells. Cells were seeded in 6 -well plates in completed medium. After $24 \mathrm{~h}$ of incubation, the cells monolayers were wounded by scratched with a 1-ml plastic pipette tip and treated with various concentration of rhinacanthin-C for $24 \mathrm{~h}$. The wound area of (A) Vero and (B) KKU-M156 cells was determined by a phase-contrast microscope at 10×magnifications. The closure of gap distance was examined by photographs of three random fields. (C) Each value represents the mean $\pm \mathrm{SD}$ of three independent experiments. ${ }^{*} \mathrm{p}<0.05, * * \mathrm{p}<0.01$, and $* * * \mathrm{p}<0.001$, vs. the DMSO group.

DMSO-treated group, whereas the migration of Vero cells was only slightly affected (Figure $3 \mathrm{~A}$ and $3 \mathrm{C}$ ). This was also confirmed by the chamber migration assay, which is semi-quantitative and showed that rhinacanthin-C significantly reduced the migration of KKU-M156 cells in a dose-dependent as shown in Figure 4A and 4B.
Anti-invasion effects of Rhinacanthin-C on KKU-M156 cells

The Boyden chamber assay was used to determine the effect of rhinacanthin-C on the invasion ability of KKU-M156 cells. Treatment with different concentrations of rhinacanthin-C significantly reduced the penetration of the Matrigel-coated filter by KKU-M156 cells in a

A Rhinacanthin-C $(\mu \mathrm{M})$

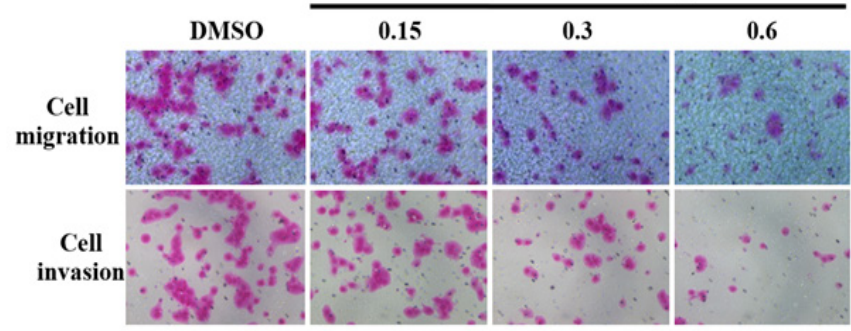

B

C
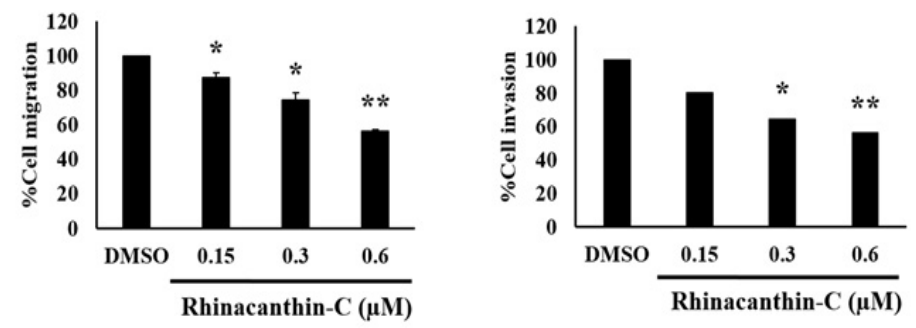

Figure 4. Effect of Rhinacanthin-C on Cell Migration and Invasion of KKU-M156 Cells. (A) A $500 \mu$ l of serum free medium containing $400 \mu \mathrm{l}$ of cells $\left(1.25 \times 10^{5}\right.$ cells $\left./ \mathrm{ml}\right)$ and $100 \mu \mathrm{l}$ of various concentrations of the compound or DMSO was added in the upper chamber of Transwell chamber (Costar) with $6.5 \mathrm{~mm}$ diameter polycarbonate membrane $(8 \mu \mathrm{m}$ pore size). After $24 \mathrm{~h}$ incubation, nonmigrative cells were removed by cotton swap and migrating cells were fixed and stained with $0.4 \%$ SRB. The percentage of $(\mathrm{B})$ cell migration and $(\mathrm{C})$ invasion was represents the mean \pm SD of three independent experiments. ${ }^{*} p<0.05$, and $* * p<0.01$, vs. the DMSO group 
A

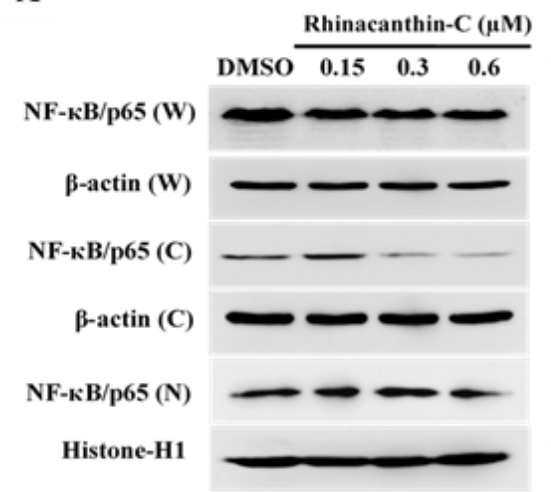

B

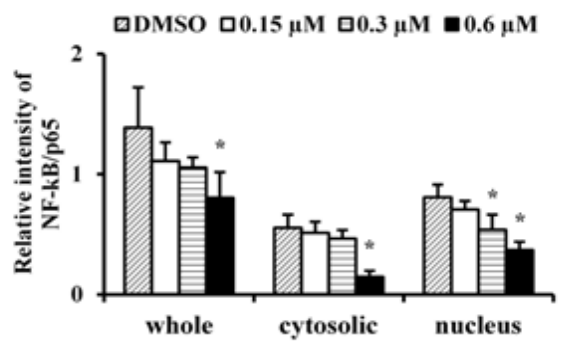

Figure 5. Reduction of NF-KB/p65 in KKU-M156 After Treatment with Rhinacanthin-C. Cells were treated with indicate dose of rhinacanthin-C for $24 \mathrm{~h}$. The total cell lysates, cytosolic and nuclear fractions were separated on SDS-PAGE and transferred to nitrocellulose membrane. (A) The membranes were probed with a primary antibody

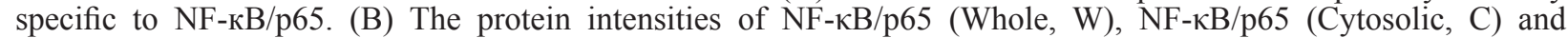
$\mathrm{NF}-\kappa \mathrm{B} / \mathrm{p} 65$ (Nuclear, N) were quantitated by densitometry and normalized to $\beta$-actin (total cell and cytosolic) and Histone H1 (nuclear lysate). Data are expressed as mean $\pm \mathrm{SD}$ of three independent experiments. ${ }^{*} \mathrm{p}<0.05$ indicate a significant difference.

dose-dependent manner (Figure 4A and 4C).

Expression changes in migration- and invasion-regulated proteins caused by the treatment of human KKU-M156 cells with rhinacanthin-C

We evaluated cytoplasmic and nuclear protein expression of NF- $\mathrm{KB}$ in KKU-M156 cells treated with rhinacanthin-C. Treatment with different concentrations of rhinacanthin-C reduced expression of NF- $\mathrm{KB} / \mathrm{p} 65$ and its translocation to the nucleus in a dose-dependent manner (Figure 5A and 5B). As shown in Figure 6A and $6 \mathrm{~B}$, treatment with rhinacanthin- $\mathrm{C}$ significantly decreased p-FAK level in a dose-dependent manner, but has no effect on the expression of FAK. Western blot analysis showed that rhinacanthin-C significantly decreased ERK1/2, p-JNK, p38 and p-p38 protein levels in a dose-dependent manner in KKU-M156 cells, but did not affect p-ERK1/2 and JNK protein expressions (Figure 7A and B).

Effect of rhinacanthin-C on the activities of $M M P-2$, $M M P-9$ and $u P A$ of KKU-M156 cells

The effects of rhinacanthin-C on activities of the proteolytic enzymes MMP-2, MMP-9 and uPA in Vero and KKU-M156 cells were determined by gelatin zymography assay. KKU-M156 cells secreted a $72 \mathrm{kDa}$ gelatinase which corresponded to MMP-2 (gelatinase A) but did not secrete MMP-9 (Figure 8A and 8B). Treatment with different concentrations of rhinacanthin- $\mathrm{C}$ significantly inhibited uPA activity in KKU-M156 cells in a dosedependent manner (Figure 9A and 9B). Vero cells did not secrete MMP-2, MMP-9 or uPA (Figure 8A and 9A).

Effects of rhinacanthin-C on expression of MMP-2 and MMP-9 protein in human KKU-M156 cells

The expression of MMPs, particularly gelatinases (MMP-2 and MMP-9), has been associated with high potential for metastasis in cancer cells. Western blot analysis showed that treatment with various concentrations of rhinacanthin-C significantly inhibited MMP-2 protein expression in KKU-M156 cells in a dose-dependent manner (Figure 10A and 10B).
A

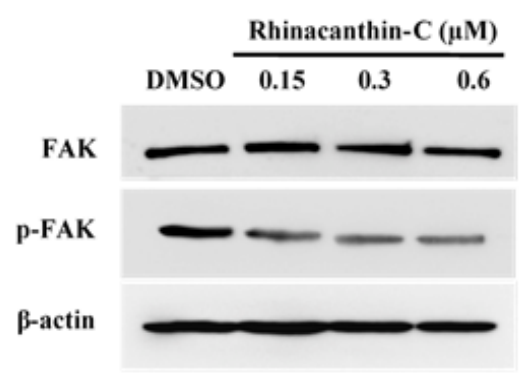

B

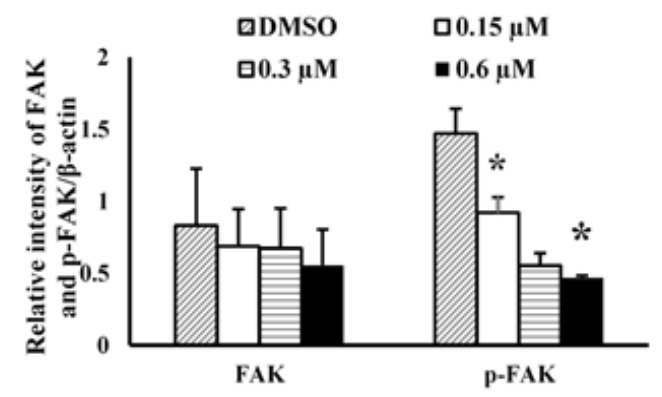

Figure 6. Inhibition of FAK and p-FAK Protein Expression by the Treatment of KKU-M156 Cells with Rhinacanthin-C. Cells were exposed with indicated concentration of rhinacanthin-C for $24 \mathrm{~h}$. Whole cell lysates were separated and transferred to nitrocellulose membrane. (A) Protein expression of FAK and p-FAK were detected by Western blot analysis. $\beta$-actin was used as an internal control to normalize the amount of protein in each experimental condition. (B) Data are expressed as mean \pm SD of three independent experiments. ${ }^{*} p<0.05$ indicate a significant difference. 
A

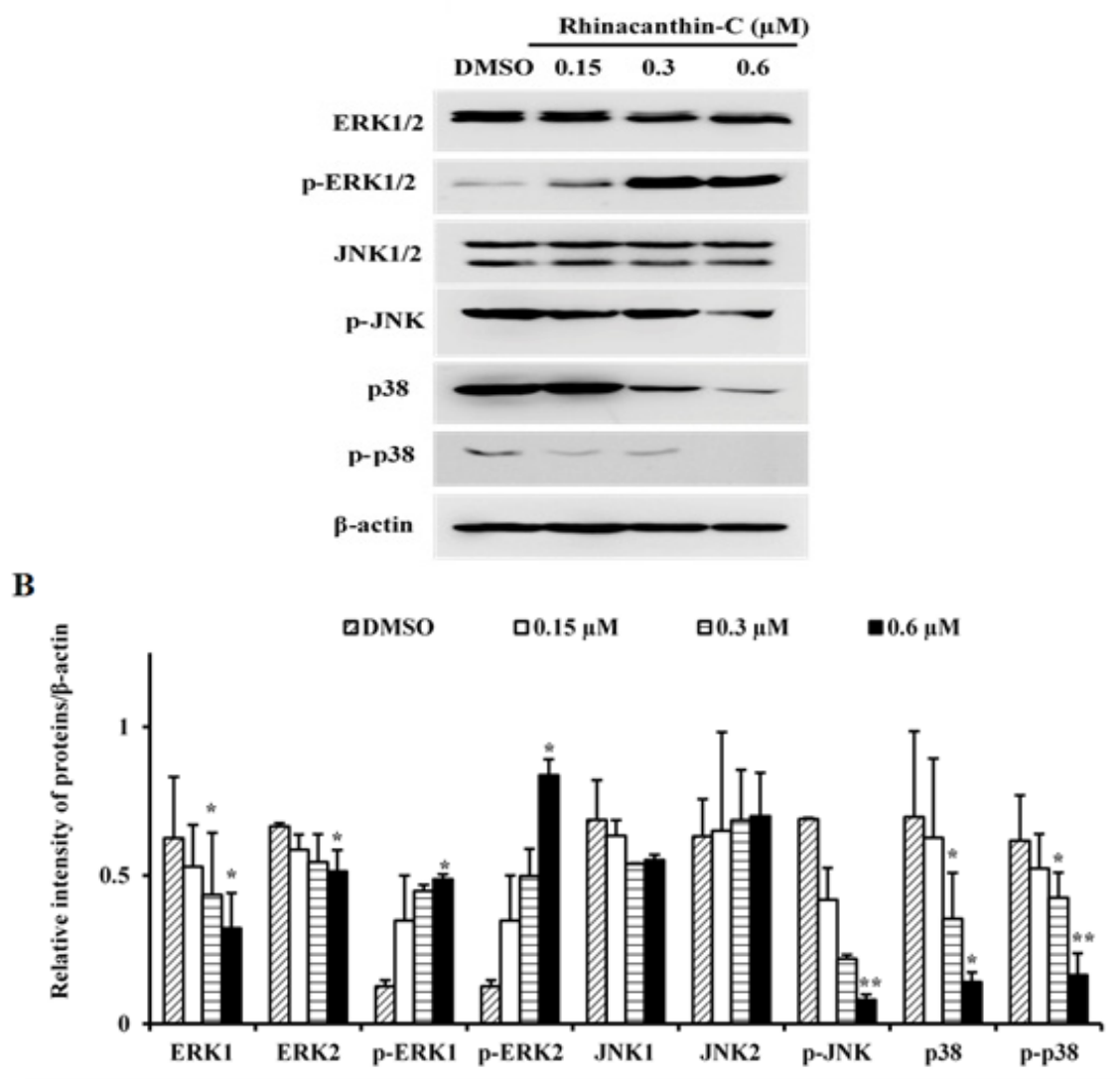

Figure 7. Inhibitory Effect of Rhinacanthin-C on the Expression of Invasion-Regulating Proteins in KKU-M156 Cells. Cells were treated with indicated doses of rhinacanthin-C for $24 \mathrm{~h}$. The total cells lysate were separated on SDSPAGE and transferred to nitrocellulose membrane. (A) Protein intensity of ERK1/2, p-ERK1/2, JNK1/2, p-JNK, p38, p-p38 were normalized with $\beta$-actin was used as an internal control. (B) Data are expressed as mean \pm SD of three independent experiments. Statistical analyses were performed using Student's t-test, $* \mathrm{p}<0.05, * * \mathrm{p}<0.01$ indicate a significant difference.

\section{Discussion}

Rhinacanthin- $\mathrm{C}$ has been reported to have anticancer effects on several types of cancer both in vitro and in vivo (Gotoh et al., 2004; Kongkathip et al., 2004; Siripong et al., 2006c). To date, no studies of the anti-metastatic effects of rhinacanthin-C on human cholangiocarcinoma cells have been done. The present study demonstrated that rhinacanthin-C showed anti-metastasis activities against a human CCA(KKU-M156) cell line. The growth inhibitory effect of rhinacanthin-C in KKU-M156 was modulated through inhibit cell migration and invasion in a dose-dependent manner. This may be mediated through decrease FAK, p38-, ERK1/2-, JNK1/2-MAPK expression, downregulate the transcription factor $\mathrm{NF}-\kappa \mathrm{B}$, leading to inhibition of MMP-2 and UPA expression. This is the first report showing that rhinacanthin-C can decrease cancer-cell invasion by suppressing the MAPK pathway and reducing expression of MMP-2 and uPA. Therefore, rhinacanthin- $\mathrm{C}$ may deserve consideration as a potential

A

B

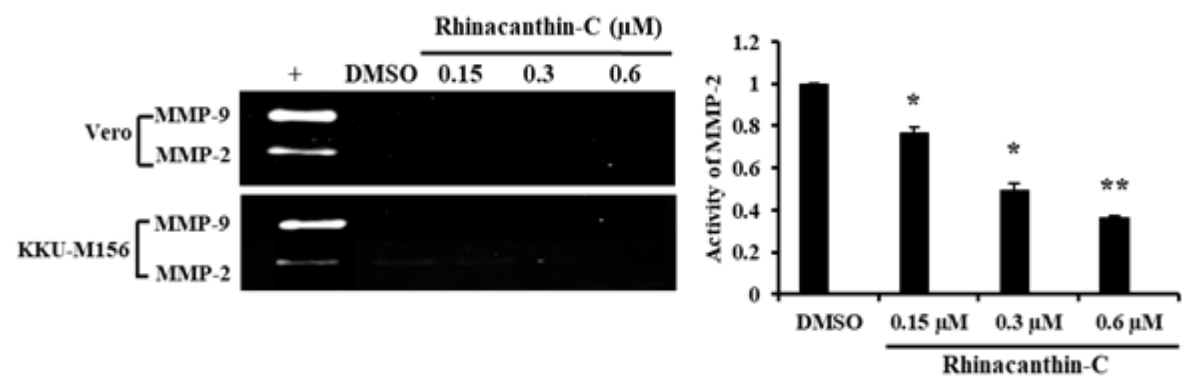

Figure 8. Inhibition of MMP-2 and -9 Activities in KKU-M156 Cells After the Treatment with Rhinacanthin-C. (A) Cells were treated with various concentrations of rhinacanthins-C for $24 \mathrm{~h}$ and the condition medium was determined by gelatin zymography. (B) The band intensities were quantified by densitometry. Data are expressed as mean \pm SD of three independent experiments. Statistical analyses were performed using Student's t-test, ${ }^{*} \mathrm{p}<0.05, * * \mathrm{p}<0.01$ indicate a significant difference. 
A

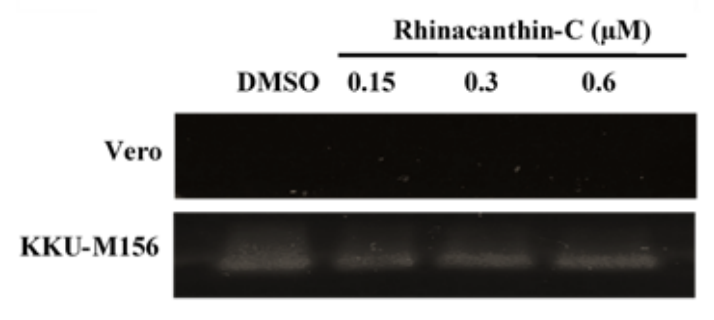

B

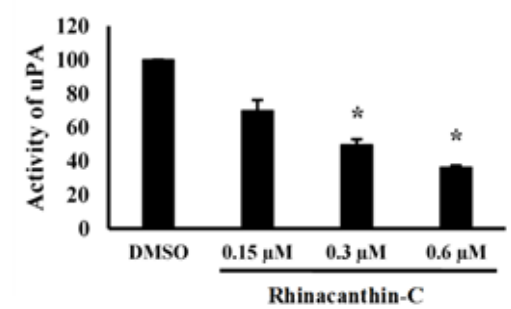

Figure 9. Inhibition of uPA Activities in KKU-M156 Cells After the Treatment with Rhinacanthin-C. (A) Cells were treated with indicated concentrations of rhinacanthins- $\mathrm{C}$ for $24 \mathrm{~h}$ and the condition medium was determined by uPA zymography. (B) The band intensities of uPA were quantified by densitometry. Data are expressed as mean \pm SD of three independent experiments. Statistical analyses were performed using Student's t-test, ${ }^{*} \mathrm{p}<0.05$ indicate a significant difference.

A

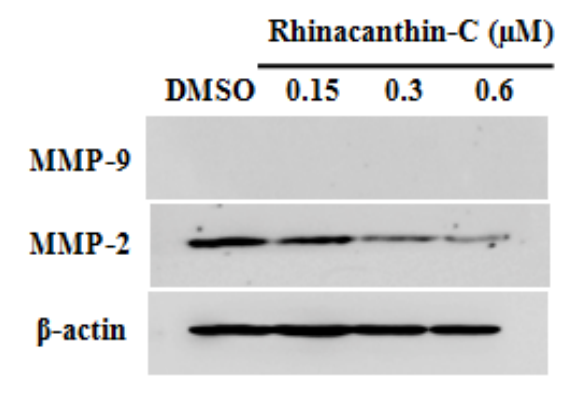

B

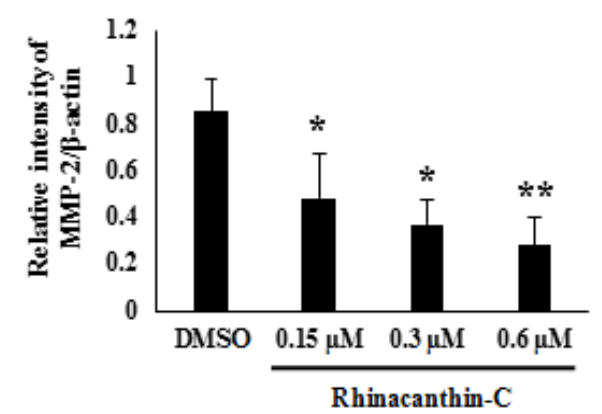

Figure 10. Reduction of MMP-2 and MMP-9 Protein Expression After Treatment with Rhinacanthin-C in KKU-M156 Cells. Cells were incubated with difference concentration of rhinacanthin-C $(0,0.15,0.3$ and $0.6 \mu \mathrm{M})$ for $24 \mathrm{~h}$. Total cell lysates were separated on 12\% SDS-PAGE and transferred to nitrocellulose membrane. (A) Protein levels of MMP- 2 and MMP-9 were detected by Western blot analysis. $\beta$-actin was used as an internal control to normalize the amount of protein in each experimental condition. (B) Data are expressed as mean \pm SD of three independent experiments. Statistical analyses were performed using Student's t-test, ${ }^{*} \mathrm{p}<0.05,{ }^{*} \mathrm{p}<0.01$ indicate a significant difference.

agent for the prevention of cancer metastasis and anticancer agent.

Cancer cell metastasis is associated with various steps including cancer cell adhesion to the ECM, proteolytic degradation of the ECM and tumor cell invasion of distant organs. Many types of cell-adhesion molecules play vital roles in different steps of the metastatic event (Miyasaka, 1995). Focal adhesion kinase (FAK) is the main mediator of signal transduction through cells and the extracellular matrix. Tyr397 phosphorylation through integrin-mediated cell adhesion to the extracellular matrix produces a binding site for different intracellular signaling molecules, such as the Src family kinases, phosphatidylinositol 3'-kinase, phospholipase C (PLC), growth factor receptor-bound protein 7 , growth factor receptor-binding protein 2 (Grb2) and SOS to activate Ras/mitogen-activated protein kinase signaling (Mon et al., 2006; Ohta et al., 2007). Increased levels of FAK expression have also been correlated with the invasive and metastatic potential of several human tumors (Weiner et al., 1993). FAK initiates a cascade of intracellular signals in response to adhesion, including MAPK activation (Seko et al., 1999). We found that rhinacanthin-C significantly decreased p-FAK protein levels in a dose-dependent manner in KKU-M156 cells. According to a previous study, the tumor suppressor gene PTEN interacts with FAK and dephosphorylates FAK to inhibit cell migration (Tamura et al., 1999).

The suppression of NF- $\mathrm{kB}$ and AP-1, downstream of the MAPK pathway, was found to inhibit MMP-2 expression, leading to potential suppression of tumor invasion and metastasis (Yang et al., 2009). Inhibition of phosphorylation in the p38-MAPK pathway was associated with downregulation of MMP-2, -9 and UPA expression (Shen et al., 2010). Several studies have suggested signal transduction pathways that can regulate the expression of MMP-2, MMP-9 and uPA in tumors (Gum et al., 1996; Lee et al., 2008). This can lead to stimulation of two transcription factor binding sites for NF- $\mathrm{KB}$ and AP-1, which play important roles in invasion and metastasis of malignant cells. NF- $\mathrm{\kappa B}$ plays a critical role in controlling MMP-2, MMP-9 and uPA expression (Gum et al., 1996; Lee et al., 2008). Therefore, our present results have confirmed that rhinacanthin-C significantly inhibits translocation of NF- $\mathrm{KB}$ into the nucleus. We have also clearly shown that rhinacanthin-C significantly inhibits the expression of phospho-FAK, p38, phospho-p38, ERK1/2, phospho-ERK1/2, JNK1/2 and phospho-JNK1/2 that are all upstream of NF- $\mathrm{KB}$, resulting in decreased activity and levels of MMP-2, MMP-9 and uPA. Thus, we conclude that inhibition of the MAPK pathway is associated with decreased production of the proteolytic enzymes MMP-2, MMP- 
9 and UPA, leading to inhibited cancer invasion. The inhibition of MMP-2 and UPA production brought about by rhinacanthin-C explains its inhibitory effect on cancer cell migration, although its effects are on cancer cell invasion, not cell adhesion (data not shown).

Cancer cell invasion and metastasis require various physiological alterations such as the upregulation of proteolytic enzymes, MMPs and uPA, which are involved in the degradation of the ECM. These are capable of inducing invasion of cancer cells into blood or lymphatic systems, leading to spread of the tumor to remote tissues or organs (Kleiner and Stetler-Stevenson, 1999). The degradation of the ECM by proteolytic enzymes, such as MMPs, is an important step for cancer invasion and metastasis (Coussens and Werb, 1996). Many reports suggest that enhanced production of proteolytic enzymes MMPs and uPA are important in this process (Kleiner and Stetler-Stevenson, 1999; Kim et al., 2001; Stetler-Stevenson et al., 1993). Here, we have demonstrated for the first time that rhinacanthin-C exerts inhibitory effects on the migration and invasion properties of KKU-M156 cells in a dose-dependent manner, as well as inhibiting the activities of MMP-2 and uPA. Cancer cells can invade host tissues by breaking off their cell-cell contacts and making new contact with the ECM, leading to low cell-cell adhesion and high cell-matrix adhesion, which is correlated with highly invasive cancer (Bohle and Kalthoff, 1999). We have found that rhinacanthin-C does not significantly change the cell-matrix adhesion properties of three CCA cell lines and Vero cells (data not shown). Therefore, we suggest that rhinacanthin- $\mathrm{C}$ does not affect cell-matrix adhesion properties.

In summary, rhinacanthin-C showed anti-metastasis activities against a human CCA (KKU-M156) cell line. The activities and protein expression levels of MMP-2 and uPA were reduced by rhinacanthin- $C$ in a dose-dependent manner. This may be mediated through decreasing FAK, p38-, ERK1/2-, JNK1/2-MAPK pathway, downregulating the transcription factor NF- $\kappa B$, leading to inhibition of the expression of MMP-2 and uPA. Therefore, rhinacanthin-C may deserve consideration as a potential agent for the prevention of cancer metastasis. In vivo testing and clinical trial of this agent on CCA patients should be performed in additional studies.

\section{Acknowledgements}

This study was supported by the Post-Doctoral Program from Research Affairs and Graduate School, Khon Kaen University (no. 58441). The present study was supported by the Center of Excellence for Innovation in Chemistry, Commission on Higher Education (Bangkok, Thailand; grant no. 4803300144), Faculty of Medicine (grant no. 58156), Khon Kaen University. We would like to acknowledge Prof. Dr. David Blair, for editing the manuscript via Publication Clinic KKU, Thailand.

\section{References}

Basset P, Okada A, Chenard MP, et al (1997). Matrix metalloproteinases as stromal effectors of human carcinoma progression: therapeutic implications. Matrix Boil, 15, 535-41.

Bohle AS, Kalthoff H (1999). Molecular mechanisms of tumor metastasis and angiogenesis. Langenbecks Arch Surg, 384, 133-40.

Bradford MM (1976). A rapid and sensitive method for the quantitation of microgram quantities of protein utilizing the principle of protein-dye binding. Anal Biochem, 72, 248-54.

Bukke S, Raghu PS, Sailaja G, Kedam TR (2011). The study on Morphological, phytochemical and pharmacological aspects of Rhinacanthus nasutus. (L) Kurz (A Review). $J$ Appl Pharm Sci, 1, 26-32.

Chung TW, Moon SK, Lee YC, et al (2002). Enhanced expression of matrix metalloproteinase- 9 by hepatitis B virus infection in liver cells. Arch Biochem Biophys, 408, 147-54.

Coussens LM, Werb Z (1996). Matrix metal loproteinases and the development of cancer. Chem Biol, 3, 895-904.

Duffy MJ, Duggan C (2004) The urokinase plasminogen activator system: a rich source of tumour markers for the individualised management of patients with cancer. Clin Biochem, 37, 541-8.

Gotoh A, Sakaeda T, Kimura T, et al (2004). Antiproliferative activity of Rhinacanthus nasutus (L.) Kurz extracts and the active moiety, rhinacanthin C. Biol Pharm Bull, 27, 1070-4.

Gum R, Lengyel E, Juarez J, et al (1996). Stimulation of 92-kDa gelatinase B promoter activity by ras is mitogen-activated protein kinase kinase 1-independent and requires multiple transcription factor binding sites including closely spaced PEA3/ets and AP-1 sequences. J Biol Chem, 271, 10672-80.

Kim D, Kim S, Koh H, et al (2001). Akt/PKB promotes cancer cell invasion via increased motility and metalloproteinase production. FASEB J, 15, 1953-62.

Kleiner DE, Stetler-Stevenson WG (1999). Matrix metalloproteinases and metastasis. Cancer Chemother Pharmacol, 43, 42-51.

Kongkathip N, Luangkamin S, Kongkathip B, et al (2004). Synthesis of novel rhinacanthins and related anticancer naphthoquinone esters. $J$ Med Chem, 47, 4427-38.

Lee SJ, Park SS, Lee US, Kim WJ, Moon SK (2008). Signaling pathway for TNF- $\alpha$-induced MMP-9 expression: mediation through p38 MAP kinase, and inhibition by anti-cancer molecule magnolol in human urinary bladder cancer 5637 cells. Int Immunopharmacol, 8, 1821-6.

Librach CL, Werb Z, Fitzgerald ML, et al (1991). 92-kD type IV collagenase mediates invasion of human cytotrophoblasts. $J$ Cell Biol, 113, 437-49.

Liotta LA, Tryggvason K, Garbisa S, et al (1980). Metastatic potential correlates with enzymatic degradation of basement membrane collagen. Nature, 284, 67-8.

Miyasaka M (1995) Cancer metastasis and adhesion molecules. Clin Orthop Relat Res, 312, 10-8.

Mon NN, Hasegawa H, Thant AA, et al (2006). A role for focal adhesion kinase signaling in tumor necrosis factor- $\alpha$-dependent matrix metalloproteinase- 9 production in a cholangiocarcinoma cell line, CCKS1. Cancer Res, 66, 6778-84.

Ohta R, Yamashita YI, Taketomi A, et al (2007). Reduced expression of focal adhesion kinase in intrahepatic cholangiocarcinoma is associated with poor tumor differentiation. Oncology, 71, 417-22.

Pinmai K, Chunlaratthanabhorn S, Ngamkitidechakul C, Soonthornchareon N, Hahnvajanawong C (2008). Synergistic growth inhibitory effects of Phyllanthus emblica and Terminalia bellerica extracts with conventional cytotoxic agents: doxorubicin and cisplatin against human hepatocellular carcinoma and lung cancer cells. World $J$ Gastroenterol, 14, 1491. 
Reddy KB, Nabha SM, Atanaskova N (2003). Role of MAP kinase in tumor progression and invasion. Cancer Metastasis Rev, 22, 395-403.

Seko Y, Seko Y, Takahashi N, et al (1999). Pulsatile stretch activates mitogen-activated protein kinase (MAPK) family members and focal adhesion kinase (p125 FAK) in cultured rat cardiac myocytes. Biochem Biophys Res Commun, 259, 8-14.

Sheets R (2000). History and characterization of the vero cell line. US Food and Drug Administration CfBEaR, ed. US Food and Drug Administration, Silver Spring, MD.

Shen KH, Hung SH, Yin LT, et al (2010). Acacetin, a flavonoid, inhibits the invasion and migration of human prostate cancer DU145 cells via inactivation of the p38 MAPK signaling pathway. Mol Cell Biochem, 333, 279-91.

Siripong P, Yahuafai J, Shimizu K, et al (2006a). Induction of apoptosis in tumor cells by three naphthoquinone esters isolated from Thai medicinal plant: Rhinacanthus nasutus KURZ. Biol Pharm Bull, 29, 2070-6.

Siripong P, Kanokmedakul K, Piyaviriyagul S, et al (2006b). Antiproliferative naphthoquinone esters from Rhinacanthus nasutus Kurz. roots on various cancer cells. Asian J Tradit Med, 23, 166-72.

Siripong P, Kanokmedakul K, Piyaviriyagul S, et al (2006c). Antiproliferative naphthoquinone esters from Rhinacanthus nasutus Kurz. roots on various cancer cells. J Pharm Biomed Anal, 23, 166-72.

Siripong P, Hahnvajanawong C, Yahuafai J, et al (2009). Induction of apoptosis by rhinacanthone isolated from Rhinacanthus nasutus roots in human cervical carcinoma cells. Biol Pharm Bull, 32, 1251-60.

Stetler-Stevenson WG, Aznavoorian S, Liotta LA(1993). Tumor cell interactions with the extracellular matrix during invasion and metastasis. Annu Rev Cell Biol, 9, 541-73.

Tamura M, Gu J, Takino T, Yamada KM (1999). Tumor suppressor PTEN inhibition of cell invasion, migration, and growth: differential involvement of focal adhesion kinase and p130Cas. Cancer Res, 59, 442-9.

Weiner TM, Craven RJ, Cance WG, Liu E (1993). Expression of focal adhesion kinase gene and invasive cancer. Lancet, 342, 1024-5.

Yang YT, Weng CJ, Ho CT, Yen GC (2009). Resveratrol analog-3, 5, 4'-trimethoxy-trans-stilbene inhibits invasion of human lung adenocarcinoma cells by suppressing the MAPK pathway and decreasing matrix metalloproteinase-2 expression. Mol Nutr Food Res, 53, 407-16.

\section{(ब) (बत}

This work is licensed under a Creative Commons AttributionNon Commercial 4.0 International License. 